\title{
LA REHABILITACION EN EL FUTURO DE CHILE
}

\author{
Prof. Dr. HERNAN ROMERO \\ Cátedra de Higieni y Medicisa Preventiva de la Universidad de Chile.
}

Para regocijo de sus cultores, la medicina se ha elevado a la condición de ciencia social al servicio de Ios hombres. Curar enfermos sigue siendo su función primordial pero no única, porque a ella se agregó, primero, la preventiva y ahora, la de rehabilitación. Justicieramente se la denomina tercera fase de la medicina o tercera medicina e incorpora procedimientos y esfuerzos destinados a devolver al lisiado $\mathrm{y}$ al convaleciente el goce máximo de salud y de capacidad económica, vocacional y social que sus limitaciones permiten.

Es axiomático que la riqueza de los paises depende, más que de sus recursos naturales, de la calidad de sus hombres. Hay muchos que, admirablemente dotados, se debaten en la miseria; otros, como Holanda o Dinamarca, han superado, obstáculo increíbles en su progreso y florecimiento. Solemos preocuparnos de la erosión de nuestro suelo o de la producción de energía eléctrica menos de lo que debiéramos, pero más que del fomento o de la reparación del capital humano. En nuestras naciones sub-desarrolladas. es imposible, por definición, justipreciar la magnitud del problema de rehabilitación. Sólo acusa su invalidez quien sabe que va a ser ayudado o protegido. Al igual que en el campo de la salud mental, también inexplorado entre nosotros, los problemas surgen $y$ se multiplican a medida que se establecen servicios de diagnóstico y tratamiento. Sucede también que las víctimas están dispersas y que el cirujano que atiende a un fracturado no sabe del reumático, del convaleciente de tuberculosis ni del ciego.

No es aventurado suponer que debe haber, en Chile, unos 150 a $200 \mathrm{mil}$ individuos que se beneficiarian positivamente de las adquisiciones modernas en materia de rehabilitación. Los cálculos más conservadores estiman este grupo en un 3 a $3 \%$ \% de la población general y estudios más acabados duplican esa proporción. En Estados Unidos: representaría el $5 \%$ del grupo de edad activa y de este número, la mitad podría ser expeditamente recuperada. Unos 20.000 incapacitados perma- nentes se hallan acogidos en nuestras instituciones de previsión y ciertamente más de la mitad de ellos seria susceptible de volver a la producción. En los diez días que siguieron a la invasión de Europa, se contaron once mil heridos en las playas de Normandía. Cantidad doble de accidentados de tránsito se registraron, en el mismo perído de tiempo, en aquel pais. Como en los témpanos, Ja masa mayor permanece escondida. Se sabe, por ejemplo, que hay más enfermedades y más accidentes entre las dueñas de casa que entre las obreras y aquellas no disponen ordinariamente de forma alguna de protección. Se sabe también que por cada diabético hay otro oculto, por 10 menos y que los defectos importantes de audición afligan a más del $1 \%$ de los adultos. En Inglaterra, cerca del $1 \%(0.8)$ de los niños asiste a escuelas especiales para defectuosos.

La rehabilitación es claramente una obligación social. Desde luego, quienes más la necesitan son los que menos poseen $y$ además forma parte sobresaliente de los programas de estímulo al desarrollo de producción y a la prosperidad. Finalmente, suscita el interés por evitar accidentes que ya son causa principalísima de derroche de vidas. Acaso no se justifica cuando los niveles económicos y de civilización son muy bajes, porque entonces puede ser menos oneroso alimentar al inválido el resto de sus días que devolverle su aptitud para el trabajo. Una vez superada esta etapa, la rehabilitación se convierte en negocio susceptible de calcular en pesos y centavos. Según la Ofjcina de Rehabilitación Vocacional de Estados Unidos, los 60.000 rehabilitados, en 1950 , aumentaron la renta nacional, el año siguiente, en 93 millones de dólares, o sea, en tres veces lo que se gastó en ellos. Con un capital de 2.300.000 dólares, Ios ciegos que venden en mácuuinas dispensadoras de artículos hicieron ganancias de 3.600 .000 dólares, en 1952. Hasta lo dos tercios de las camas de sanatorios y hospitales para tuberculosos suelen estar ocupadas por pacientes que han recaído. Rehabilitarlos con ocasión de la primera alta es aquí ahorro y prevención. 
Para los hebreos antiguos, la invalidez representaba castigo de pecados y forma de expiación; para los griegos, inferioridad y para los primeros cristianos, el camino de la gracia. Frente a elia, casi todos tienen prejuicios o alguna forma fija de reaccionar. La compasión suele servirles de pretexto para excusarse de tomar medidas constructivas de verdadera ayuda. Hoy está demostrado que la abrumadora mayoria de los lisiados - el $97 \%$ según el Instituto Americaro para Listados e Inválicos - puede llenar funciones de un tipo u otro. En Holanda, la ley obliga a emplear un $2 \%$ de ellos en toda empresa que tenga más de 50 empleados y en terra, un $3 \%$ de los registrados, sí los obreros exceden de 20. Ford Motor Company los ha estado utilizando ampliamente $y$ se manifiesta muy satisfecha de su rendimiento $\mathrm{y}$ en la fábrica de cosméticos $y$ productos farmacéuticos de Barr, en Chicago, fundada por un sordomudo y un amputado, la casi total.tad de los emrleados tiene alguna forma de invalidez. Para cada uno de ellos habría virtualmente, algún oficio compatible.

Escrutinios prolijos han revelado que el rendimiento de los lisiados en ocupaciones adecuadas es ligeramente mayor que el de personas sanas y que sus inasistencias o los riesgos que corren ellos mismos o exponen a los demás no ofrecen diferencia sensible respecto al otro grupo. Ordinariamente compensan en exceso sus deficiencias y el ciego, a fuerza de tacto, suele desempeñar mejor la tarea que importan repetición rápida y exacta como los sordos, las faenas ruidosas. En Estados Unidos, la asociación certeramente denominada "Posibilidades Ilimitadas" buscan empleo a los amputados y la misma función cumple la Fraternidad de los Patas de Palo. Desde 1945, se celebra, en Octubre, la Semana Nacional para Emplear al Lisiado Físico. En dos años, logró duplicar el contingente, que hoy constituye más o menos el $10 \%$ del total de los trabajadores.

El médico solía amenazar al cardiópata de muerte si reanudaba sus ocupaciones. Le daba así la alternativa de fallecer de hambre o de hastía, sentado en un silón. Hoy lo autorizan y le piden que despliegue todo el esfuerzo que su corazón toelra. Sabe, además, que sólo en las emergencias echamos mano verdaderamente de nuestras capacidades y que en la eviden- cia cotidiana, sólo empleamos una fracción. Exageradamente se postuló que el reposo en cama es una enfermedad en sí. porque, en realidad, magnifica los procesos mórbidos de desadaptación y disminuye, por ejemplo, la capacidad vital de los pulmones y el volumen de sangre. De todos modos, debe ser prescrito lo mismo que los medicamentos, la dieta y otras formas de tratamiento. Se ha postulado, también, que el encamado sufre un $10 \%$ de dolor o molestia y un $90 \%$ de tedio. Las altas impuestas y las fugas constituyeron azote en nuestros sanatorios. Cuando abundan, hablan mal del establecimiento.

Es cierto que la acción absorbe y neutraliza la ansiedad; pero no es cuestión de mantener al paciente siempre en actividad sino de que ésta contribuya al proceso de recuperación. Se fabrican hoy pianos vara colocar sobre la cama y la música o la literatura puede devolver al paciente la confianza en sí mismo. Procede evidentemente que el acondicionamiento sea precoz, progresivo y motivado, como dicen los pedagogos. Aún en enfermedad tan humoral como la neumonía, la convalecencia $y$ las recaídas disminuyen en un $30 \%$ o $40 \%$ mediante la rehabilitación sistemática. Cuanto mayor será el beneficio en las fracturas o en las dislocaciones articulares, en las parálisis y otros cuadros neurológicos, en las artritis y en mil procesos más. Aunque el paciente mismo no produzca, basta que se valga por sí mismo para que desocupe manos que se pueden emplear en otras tareas.

Hasta ahora, no hay modelo de prótesis calificable de ideal. Como las dentaduras postizas, el ojo o la pierna artificial, ha de ser adaptada al sujeto. El cirujano sabe que, en igualdad de circunstancias, debe amputar el miembro inferior más lejos de la raíz si se quiere obtener deambulación menos anormal y más cerca, si se trata de lograr firmeza, como en el caso del campesino o del gañán. Son incontables los inválidos que prescinden de sus prótesis y se resignan a las muletas o a la silla de ruedas, simplemente porque la elección fué defectuosa o porque no se les enseñó a emplearlas. Por otro lado, Douglas Bader, el autor de "Reaching for the Sky" jugaba golf con sus piernas mecánicas y ellas no fueron abstáculo para que derribara 24 aviones nazis y dirigiera una escuadrilla aérea, durante la últi- 
ma guerra. Cuando uno vé, en Nueva York, a un paraplégico, que carece absolutamente de movimiento y sensibilidad en las extremidades inferiores, subirse a un ómnibus del servicio público; cuando uno observó al Presidente Roosevelt fijar las varillas metálicas que le permitian mantenerse de pie después que sus hijos o sus edecanes lo habían ayudado a pararse; cuando uno ha contemplado a una ciega tomar dictado y transcribirlo a máquina, no puede dudar de la rehabilitación.

En Chile, algunas leyes de protección económica rayan en la prodigalidad. Evidentemente un obrero que está percibiendo la totalidad de su salario no tiene mucha prisa y puede aún sufrir de "pensionitis". Su rehabilitación debería interesar más al empleador o a la institución aseguradora. Es curioso que éstos se hayan demorado tanto en entenderlo así y en el informe de Beveridbe uno lee que, en cerca de medio siglo, el sistema que manejó, en Inglaterra, los accidentes y enfermedades industriales, hizo poco o nada por lo más importante y primero, o sea por la restauración del dañado al mayor grado de producción y en el mínimo de tiempo. La compensación monetaria es automátíca y debería ocupar posición subalterna. Hoy es así $y$ en los países progresistas se advierte movimiento formidable en favor de la rehabilitación.

Tiempo hubo en que las familias ocultaban a los espásticos, las esclerosis múlitiples y otros enfermos nerviosos como si constituyeren verguenza. La sociedad los relegaba en instituciones fatídicas, que recordaban Ia Corte de los Milagros y, en general, daba la sensación de destinar rincones para amontonar los deshechos humanos. Recuperarlos constituye acto humanitario $y$ proposición financieramente provechosa. En Londres, ha visto uno barrios donde el interior de las casas está calculado para que las sillas de ruedas puedan circular libremente $y$ donde hay. profusión de asas y otros medios que permiten a los inválidos desplazarse al baño o a la cama. Los ha visto también movilizarse en sillas de ruedas motorizadas o en automóviles que se conducen sin el empleo de Ios pies. En el Instituto de Rusk, la rehabilitación logró que la proporción de confinados en esos adminículos descendiera de $68 \%$ a $32 \%$ y los capaces de algún trabajo subieran de $17,2: a \cdot 67,1 \%$ en un año.
La Comisión que, por encargo del Presidente Eisenhower, estudió las necesidades sanitarias, recomendó que el $20 \%$ de las camas de hospitales que cuenten con más de doscientas se destinen a convalecientes y a rehabilitación. Aquí donde disfrutamos del privilegio, desde el purito de vista médico, de pertenecer a un sistema unitario, no tendriamos para que diseminar tanto el problema. No se justificaría mantener en hospitales, donde el gasto diario del enfermo es alto, a meros convalecientes ni multiplicar, a la inversa, dotaciones costosas. Nada excusa, eso sí, al Servicio Nacional de Salud, al Servicio de Seguro Social y a las otras instituciones médicas y de previsión de iniciar prontamente una política nacional y de gran envergadura para abreviar las convalecencias y disminuir su costo, como también para impulsar la rehabilitación física, mental, vocacional y social de los Jisiados.

Al extranjero suele sorprender la cantidad de inválidos que circulan por nuestras calles y que contrasta con muchas"expresiones de nuestro progreso. Entre ellos, abundan los que se sienten derrotados y se dan al vicio o se tornan cínicos. La sociedad tiene, frente a ellos, responsabilidades ineludibles, que, egoístamente, le conviene afrontar. Acaso nadie aconsejaría hoy despeñarlos desde la roca Tarpeya, pero no faltan quienes contemplan el fenómeno con indiferencia. En cambio, varios médicos se han estado esforzando por suplir esta deficiencia y en distintas partes del país han surgido pequeños servicios que compensan la escasez de recursos con abnegación y eficiencia. Ha llegado el momento de que las autoridades de Gobierno, los industriales, los comerciantes y otros empresarios les den verdadero respaldo y los medios con que trabajar mejor y en mayor escala. 'Además de inhumano, es miope descuidar la protección y la restauración del capital humano. La'rehabilitación, como ciencia y como arte, ha alcanzado grado tal de perfeccionamiento que sus resultados se pueden estimar en pesos y centavos. Oslers dijo de la tuberculosis que es una enfermedad social en la que se juega un factor médico. Frente a los lisiados y a los convalecientes, nuestros especialistas han desarrollado técnicas y sistemas de considerable eficacia. Para ponerlos en juego, necesitan la colaboración y el respaldo de las autoridades, de los empresarios y de la colectividad. 